\title{
Panorama da imagem social da enfermeira divulgada na mídia impressa
}

Overview of nurses' social image published in the print media

Situación de la imagen social de la enfermera divulgada en los medios de comunicación impresos

Miller Fontes Brandão ${ }^{1}$ Đi https://orcid.org/0000-0003-2929-1115

Gillberto Tadeu Reis da Silva ${ }^{1}$ @ nttps://orcid.org/0000-0002-0595-0780

Giselle Alves da Silva Teixeira ${ }^{1}$ io https://orcid.org/0000-0001-6245-302X

Leonardo Fernandes Nascimento² (1) https://orcid.org/0000-0003-2929-1115

Paulo Joaquim Pina Queirós ${ }^{3}$ iD hitps://orcid.org/0000-0003-1817-612X

Maria Angélica de Almeida Peres ${ }^{4}$ ie https://orcid.org/0000-0002-6430-3540

Aline Di Carla Laitano ${ }^{5}$ iD https://orcid.org/0000-0003-0317-6741

Victor Porfírio Ferreira Almeida Santos ${ }^{1}$ io https://orcid.org/0000-0002-7408-4150

Como citar:

Brandão MF, Silva GT, Teixeira GA, Nascimento

$L F$, Queirós PJ, Peres MA, et al. Panorama

da imagem social da enfermeira divulgada na mídia impressa. Acta Paul Enferm. 2021;34:eAPE002935.

DOI

http://dx.doi.org/10.37689/actaape/2021A0002935

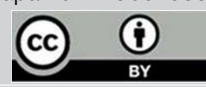

Descritores

Enfermeiras e enfermeiros; Meios de comunicação de massa; Notícias; Papel do profissional de enfermagem; Valorização social

Keywords

Nurses; Massa media; Notices; Nurse's role; Social desirability

Descriptores

Enfermeras y enfermeros; Medios de comunicación de masas; Noticias; Rol de la enfermera;

Deseabilidad social

Submetido

5 de Outubro de 2020

Aceito

3 de Dezembro de 2020

Autor correspondente

Miller Fontes Brandão

E-mail: miller_brandao_100@hotmail.com

\section{Resumo}

Objetivo: Apresentar um panorama da imagem social da enfermeira divulgada na Mídia Impressa brasileira no período de 1970 a 1999.

Métodos: Estudo exploratório, documental, quantitativo que utilizou como fonte de dados as edições publicadas pelo Jornal Estado de São Paulo nos 30 anos compreendidos entre 1970 e 1999, que mencionaram o termo "enfermeira" ou "enfermeiro", identificadas por meio de webscraping. 0 tratamento e a análise das notícias foram realizados com auxílio do software Sphinx.

Resultados: Foram identificadas 10.950 edições do jornal e 2.528 notícias que mencionavam os termos "enfermeiro" ou "enfermeira". Identificamos uma média de sete notícias por mês a respeito da enfermeira. Entretanto, em 90,3\%, a enfermeira foi apenas mencionada no texto, sem nenhum destaque ou relação com a notícia principal. Além disso, a maior parte das matérias foi veiculada na seção classificados, no formato de artigo ou coluna, que, por característica constitutiva, traz a opinião do autor sobre determinado tema.

Conclusão: Podemos inferir, com base nos dados analisados, que apesar do significativo quantitativo de notícias publicadas a respeito do tema durante o período analisado, isso pouco contribuiu para a construção da imagem da enfermeira enquanto profissional de saúde na sociedade brasileira porque a maior parte das notícias apenas mencionou a enfermeira no texto ou utilizou o termo para caracterizar um objeto ou situação.

\section{Abstract}

Objective: to present an overview of nurses' social image published in the Brazilian Printed Media from 1970 to 1999.

Methods: this is an exploratory, documentary, quantitative study, which used as a data source the editions published by Estado de São Paulo in the 30 years between 1970 and 1999, which mentioned the term "nurses", identified through web scraping. News processing and analysis carried out using the Sphinx software.

Results: 10,950 issues of the newspaper and 2,528 news items that mentioned the term "nurses" were identified. We identified an average of seven news a month about nurses. However, in $90.3 \%$, nurses were only mentioned in the text, without any highlight or relationship with the main news. Furthermore, most articles were published in the classified section, in the form of an article or column, which, by constitutive characteristic, brings the opinion of the author on a given topic.

Conclusion: we can infer, based on the analyzed data, that despite the significant amount of news published on the subject during the analyzed period, this contributed little to constructing the image of nurses as health 
professionals in Brazilian society because most of the news only mentioned nurses in the text or used the term to characterize an object or situation.

\section{Resumen}

Objetivo: Presentar cómo es la situación de la imagen social de la enfermera divulgada en los medios de comunicación impresos brasileños de 1970 a 1999.

Métodos: Estudio exploratorio, documental, cuantitativo que utilizó como fuente de datos las ediciones publicadas por el periódico Estado de São Paulo durante los 30 años comprendidos entre 1970 y 1999, que mencionaron el término "enfermera" o "enfermero", identificadas mediante webscraping. Las noticias fueron tratadas y analizadas con ayuda del software Sphinx.

Resultados: Se identificaron 10.950 ediciones del periódico y 2.528 noticias que mencionaron los términos "enfermero" o "enfermera". Identificamos un promedio de siete noticias por mes relacionadas con enfermeras. Sin embargo, en el 90,3\% de los casos, la enfermera solo fue mencionada en el texto, sin ningún tipo de énfasis o relación con la noticia principal. Además, la mayor parte de las notas fue publicada en la sección de clasificados, en formato de artículo o columna, que, por característica constitutiva, expone la opinión del autor sobre determinado tema.

Conclusión: Con base en los datos analizados, podemos deducir que, a pesar de la cantidad significativa de noticias publicadas sobre el tema durante el período estudiado, contribuyó poco en la construcción de la imagen de la enfermera como profesional de la salud en la sociedad brasileña, porque en la mayoría de las noticias solo se mencionó a la enfermera en el texto o se utilizó el término para caracterizar un objeto o situación.

\section{Introdução}

A imagem positiva de qualquer profissão na sociedade pode resultar em poder, reconhecimento e status. Tudo o que se imagina sobre determinada categoria profissional é tão relevante quanto aquilo que ela realmente é, pois a repercussão de uma imagem criada pode favorecer ou dificultar o desenvolvimento de uma profissão, a sua valorização e o seu reconhecimento social. ${ }^{(1)}$

Nesse sentido, a mídia, na condição de instrumento de veiculação de mensagens e informaçóes na sociedade, assume um papel estratégico como (re)produtora de discursos que contribuem para formação de determinadas imagens de sujeitos, instituições e profissóes. Contudo, deve-se considerar que este canal de transmissão sempre apresenta os fatos sob determinada perspectiva, a qual pode estar velada ou explícita nas notícias veiculadas, sendo esta imparcialidade inerente à atividade jornalística.

Necessário ainda reconhecer a presença de vieses na divulgação e/ou exposição de realidades pelos meios de comunicação. ${ }^{(2)} \mathrm{O}$ discurso midiático, portanto, ao relatar acontecimentos, produzir sentidos e buscar influenciar seus leitores, evidencia o poder simbólico de alguns agentes e grupos sociais. ${ }^{(3)}$

No que se refere à área da saúde, é comum que a mídia privilegie os interesses da população pelo meio jornalístico e a exposição midiática, frente a legitimidade dos fatos e eventos ocorridos, seja tendenciosa com fins de agradar os espectadores. ${ }^{(4)}$

Nesse contexto, reconhecemos a influência da mídia na construção da imagem da Enfermagem ao longo de sua existência, enquanto campo profissional, no Brasil. Assumimos também que as constantes mudanças em atividades e perfil de profissionais da Enfermagem ao longo da história contribuíram para a concepção do que este campo profissional verdadeiramente é e do seu significado social.

Entretanto, a forma como a prática da Enfermagem e suas mudanças foram veiculadas na sociedade por meio da mídia é sensivelmente importante para a construção da imagem desta profissão, tanto que o peso desta divulgação ainda ecoa na imagem que grande parte da sociedade tem a respeito das três categorias que compóem o campo da enfermagem brasileira: Enfermeira, Técnico de Enfermagem e Auxiliar de Enfermagem. ${ }^{(5)}$ É comum, por exemplo, que as três profissóes sejam mencionadas em reportagens sem qualquer diferenciação entre seus saberes e atuaçôes, em um sinal de que, para a mídia em geral, a enfermagem é uma massa homogênea traduzida exclusivamente na figura da enfermeira.

Neste contexto, esta profissional tem sido citada como uma das mais impactadas pela divulgação na mídia, uma vez que está presente em quase todos os serviços de saúde e, geralmente, assume o papel de gerente intermediária, ou seja, gerencia não apenas o cuidado em enfermagem, mas também o cuidado em saúde. Assim, ela acaba se expondo mais às diversas situaçóes, inclusive àquelas com desfechos negativos, os quais, embora nem sempre dependam da sua atuação, são a ela diretamente atribuídos pelos meios de comunicação. ${ }^{(5,6)}$

A elevada frequência com que isso ocorre dificulta que as pessoas não inseridas nesse cotidiano 
identifiquem e compreendam adequadamente as diversas responsabilidades por esses acontecimentos, deixando a impressão, da forma como são narrados pela mídia, que resultam de um ato exclusivo de uma única profissão e não de uma confluência de açóes e responsabilidades.

Consideramos importante destacar também que a mídia, ao mesmo tempo em que divulga os eventos negativos, também evidencia as lutas e os movimentos empreendidos pela enfermagem em busca de mudanças nas políticas de formação e de saúde, bem como nas condiçôes e relações de trabalho. ${ }^{(5,6)}$

Entendemos que a imagem profissional da enfermeira é continuamente construída e influenciada pelo momento histórico vivido. Sob uma análise retrospectiva, são notórias as diferentes imagens atribuídas pela imprensa a esta profissional ao longo dos anos, sobretudo no que se refere aos movimentos sociais e de lutas da categoria. Paralelamente, também identificamos o quanto esta divulgação reverbera na imagem socialmente construída e propagada a respeito desta profissão, sob diversos outros aspectos. $^{(7-9)}$

Diante do exposto, e cientes de que a mídia impressa desempenha papel crucial no reconhecimento, poder e status da enfermagem, buscamos neste estudo apresentar um panorama da imagem social da enfermeira divulgada na mídia impressa brasileira no período de 1970 a 1999.

Por se tratar de um meio de comunicação que estimula discussóes e debates em diversos espaços públicos e privados, informando e suscitando reflexôes em inúmeros leitores, acreditamos ser relevante, para melhor entendimento da construção social da imagem da enfermeira, conhecer o histórico de reportagens publicadas neste importante periódico nacional. Destacamos ainda que, no período delimitado para este estudo, o referido jornal exercia grande influência na sociedade brasileira.

\section{Métodos}

Trata-se de uma pesquisa exploratória, do tipo documental, de abordagem quantitativa. O intuito foi evidenciar um panorama das notícias publicadas no jornal O Estado de São Paulo a respeito da atuação de enfermeiras no período de 1970 a 1999. A pesquisa documental utiliza de métodos para a análise e compreensão de documentos variados e assim permite a obtenção de uma riqueza de informaçóes ao estudo ao aproximar o objeto de estudo de suas fontes e contextos histórico e sociocultural. ${ }^{(10)}$ A fonte de coleta de dados ocorre por meio de documentos escritos ou não sendo esses sua fonte primária. ${ }^{(11)}$

Escolhemos este periódico por apresentar, nas décadas investigadas, grande repercussão nacional, além de amplo alcance, confiabilidade e influência sobre a opinião de seus leitores. É também o mais antigo periódico ainda em atividade no país, tendo como data de fundaçáo de 4 de janeiro de 1875 .

Utilizamos como fonte de dados todas as ediçôes publicadas pelo jornal nos 30 anos compreendidos entre 1970 e 1999 . Válido mencionar que este periódico tem circulação diária e que não deixou de ser publicado em nenhum momento do recorte estudado, o que totalizou 10.950 ediçóes publicadas no recorte temporal estudado. $\mathrm{O}$ acervo deste jornal está disponível e os exemplares da época de interesse para este estudo encontram-se, inclusive, digitalizados e disponíveis gratuitamente.

Assim, por meio de técnicas de webscraping, procedimento em evidência para coleta automatizada de dados on-line, também chamada Coleta de Dados Web, foram identificadas 11.000 notícias publicadas entre 01 de janeiro de 1970 e 31 de dezembro de 1999. ${ }^{(12)}$

Adotamos, como critério de inclusão para este estudo, a menção aos termos "enfermeiro" ou "enfermeira", bem como ambas as palavras nos seus respectivos plurais, em qualquer momento do texto, nas notícias publicadas nos seguintes formatos: reportagens, colunas, manchetes, artigos e entrevistas. Assim, a população do estudo foi composta pelas 2.528 notícias selecionadas dentre as 10.950 edições do jornal analisadas por serem notícias que mencionaram a enfermeira(o) em algum momento.

O tratamento e a análise das notícias foram realizados com auxílio do software Sphinx - uma ferramenta para análise de dados quantitativos e qualitativos. O Sphinx tem seu funcionamento baseado em quatro etapas: (1) elaboração do questionário ou 
instrumento de pesquisa, (2) coleta das respostas, (3) preparação dos dados e, por fim, (4) análise consolidada dos dados e divulgação de relatórios.

O primeiro passo foi inserir no software um questionário contendo as seguintes informaçóes sobre as notícias: data de publicação, tipo de autor da notícia, seção em que foi publicada, formato e características de vinculação da imagem da enfermeira (figura principal, figura secundária ou apenas citação). Em seguida, as 2.528 notícias foram analisadas individualmente com base nas variáveis investigadas.

O software Sphinx permitiu a tabulação dos dados caracterizados em cada matéria, gerando gráficos e tabelas com frequências absolutas e relativas, assim como o cruzamento entre as características de análise.

As normas propostas pelo Comitê de Ética em Pesquisa definido na resolução no 466 , de 12 de dezembro de 2012, de Conselho Nacional de Saúde, pesquisa documental e que emprega documentos públicos de acesso gratuito à população, faz-se dispensável a submissão ao Comitê de Ética em Pesquisa. Assim, refuta-se frente a resolução no 510 de 07 de abril de 2016, no qual náo serão registrados e avaliados pelo Comitê de Ética em Pesquisa, pesquisas que usam informação pública em termos da lei $n^{\circ} 12.527 / 2011$ e pesquisas que informações uso do domínio público.

De acordo com a legislação vigente no país, imagens e reportagens jornalísticas escritas são conside- radas obras intelectuais protegidas por lei específica, conforme Art. 7 da Lei 9610/98, que altera, atualiza e consolida a legislaçáo sobre direitos autorais. Dessa forma, foram garantidos todos os direitos autorais dos materiais utilizados nesta pesquisa, bem como a real descrição dos conteúdos analisados.

\section{Resultados}

As 2.528 notícias analisadas foram publicadas ao longo de 30 anos, conforme distribuição apresentada na figura 1. A média de notícias publicadas nos 360 meses analisados foi de sete notícias/mês, com destaque para os anos de 1979 e 1975, que apresentaram, respectivamente, o maior (127 total e 10,58/ mês) e o menor (52 total e 4,33/mês) número de notícias publicadas a esse respeito.

As notícias em um jornal podem ser escritas por diferentes sujeitos - desde jornalistas até leitores, os quais podem enviar suas observaçóes e sugestóes ao editor. Assim, classificamos as notícias conforme o tipo de autor (Figura 2).

Alertamos para a variedade de autores e, paralelamente, para a diversidade de formatos em que essas notícias foram publicadas, entendendo que o formato da notícia interfere na ênfase e no conteúdo apresentado (Figura 3).

A manchete se caracteriza por ser um título no jornal, grafado com letras grandes, geralmente formado por uma frase de efeito concisa e destacada na

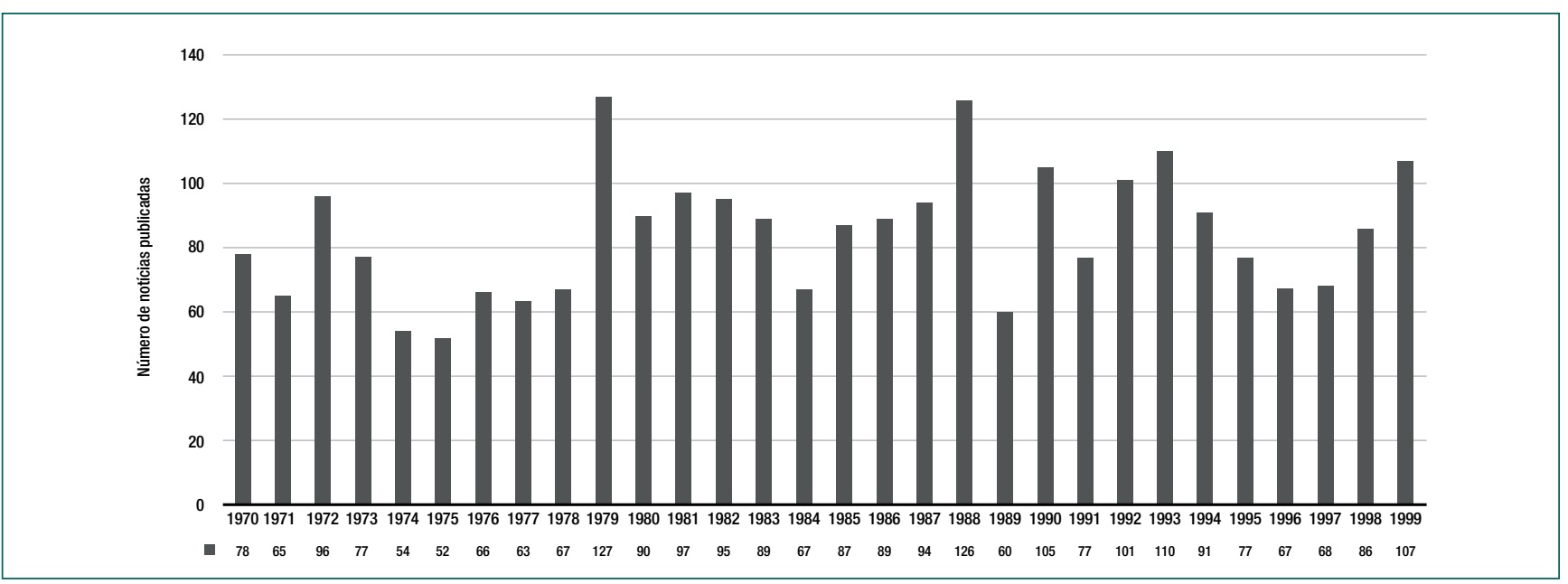

Figura 1. Notícias publicadas sobre enfermeiras no jornal O Estado de São Paulo no período de 1970 a 1999 


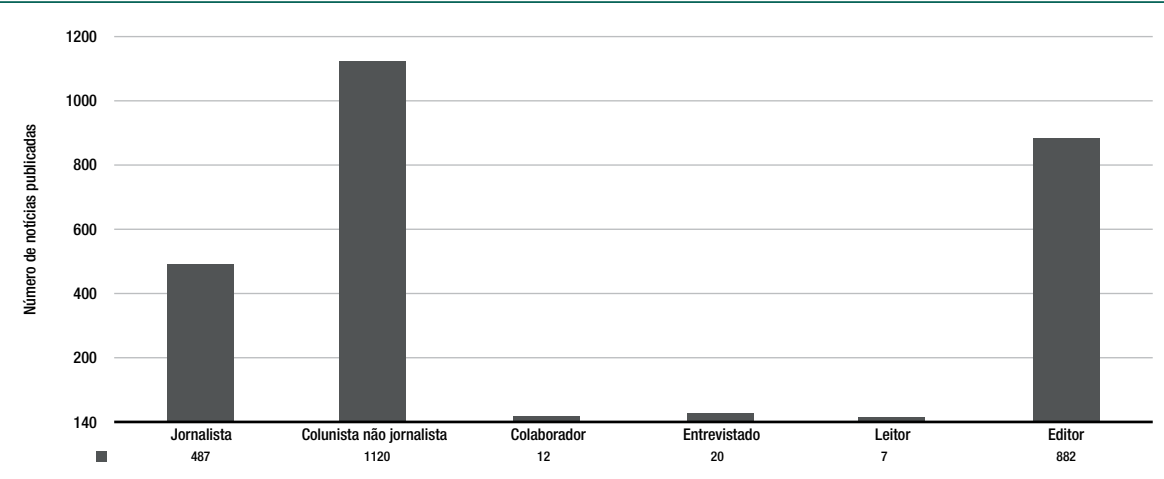

Figura 2. Notícias publicadas sobre enfermeiras no jornal O Estado de São Paulo no período de 1970 a 1999 conforme tipo de autor

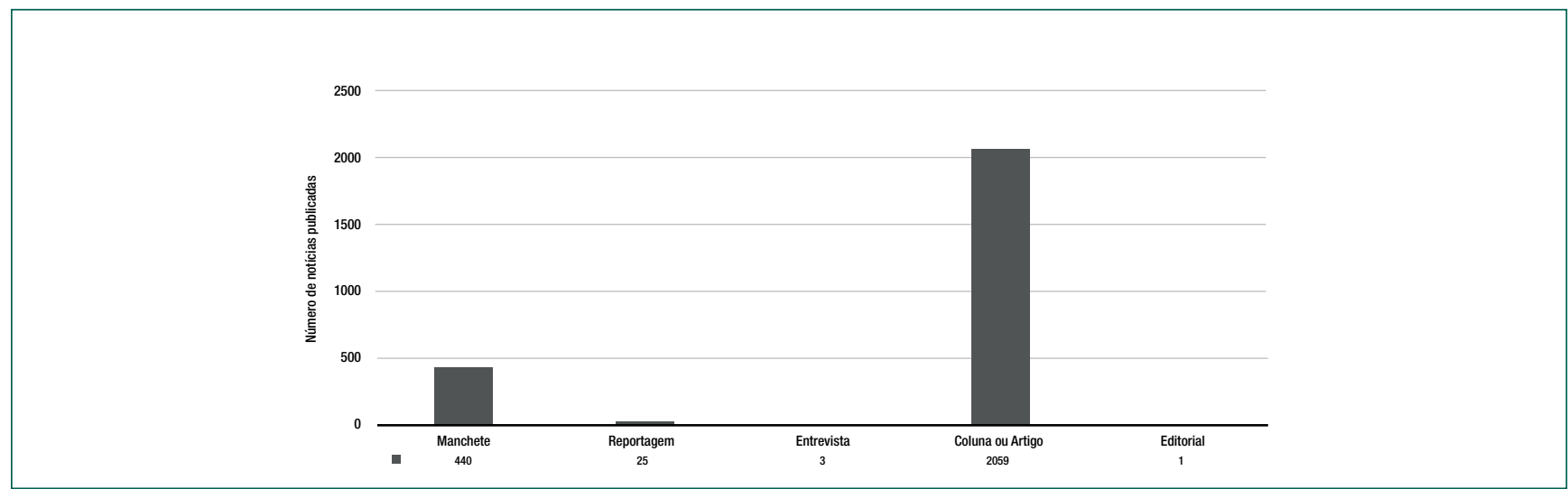

Figura 3. Notícias publicadas sobre enfermeiras no jornal 0 Estado de São Paulo no período de 1970 a 1999 conforme 0 formato

primeira página. ${ }^{(13)} \mathrm{O}$ artigo ou coluna é um texto eminentemente opinativo que traz no seu bojo a visão do autor sobre determinado assunto. ${ }^{(14)} \mathrm{A}$ entrevista consiste na coleta de declaraçóes tomadas pelo jornalista para divulgação no jornal e, portanto, traz a opinião ou as ideias do entrevistado. ${ }^{(15)} \mathrm{A}$ reportagem é um conteúdo jornalístico baseado no testemunho direto dos fatos e situaçóes explicadas em palavras e, sob uma perspectiva mais atual, por histórias vividas por pessoas, relacionadas ao seu contexto. ${ }^{(14)}$

Por fim, as notícias foram classificadas conforme a menção ao termo enfermeira/enfermeiro. Consideramos três variáveis: figura central, quando a enfermeira foi o assunto principal da notícia publicada; figura secundária, quando citada no papel de coadjuvante na informação divulgada e atrelada à figura central; e figura mencionada, quando apenas citada na notícia, sem destaque ou enfoque sobre o tema principal.

Em 2276 notícias, a enfermeira foi apenas mencionada; apareceu como figura central em 188 no- tícias e em 64 a enfermeira era figura secundária. Ao relacionar as três décadas estudadas com o quantitativo de notícias nas quais a enfermeira aparece como figura central, identificamos $20(10,6 \%)$ na década de 1970; $36(19,14 \%)$ na década de 1980; 132 (70,21\%) notícias na década de 1990 .

\section{Discussão}

Os resultados deste estudo apontam para a pouca visibilidade da enfermeira enquanto profissão no Jornal O Estado de São Paulo no período analisado.

Identificamos que a figura da enfermeira esteve presente em um número considerável de edições do jornal O Estado de Sáo Paulo. Ao longo do período investigado, identificamos média de sete notícias por mês a respeito desta profissional.

Entretanto, em quase todas (90,3\%), a enfermeira foi apenas mencionada no texto, sem nenhum destaque ou relação com a notícia principal. Além 
disso, a maior parte das matérias foi veiculada na seção classificados, no formato de artigo ou coluna, que, por característica constitutiva, traz a opiniáo do autor sobre determinado tema.

Reconhecemos que a contribuição da mídia impressa para a construção de conhecimentos/imagens na sociedade está relacionada à garantia de princípios como jornalismo de objetividade, imparcialidade e veracidade dos fatos. No entanto, os enquadramentos adotados na publicação permitem saber sob quais perspectivas os assuntos são apresentados e, também, de que forma será construída a imagem pública daqueles envolvidos nas narrativas. $\mathrm{O}$ enquadramento pode jogar luz em aspectos específicos de um evento ou assunto. ${ }^{(2,5)}$

Com base nos resultados obtidos e analisados, podemos afirmar que as notícias veiculadas no jornal $O$ Estado de São Paulo no período investigado pouco contribuem para a construção da imagem da enfermeira como profissional da saúde. São notícias que, em sua maioria, utilizam o termo enfermeira como adjetivo para caracterizar algum objeto ou situação que tem pouca ou nenhuma relação com o exercício profissional.

Além disso, não é incomum que as notícias referentes a enfermeiras estejam ligadas a erros na prestaçáo da assistência ou a estereótipos criados em torno da imagem dessa profissional.

Estudo realizado com enfermeiros israelenses ${ }^{(16)}$ identificou tendência de que os meios de comunicação e mídias reforcem aspectos negativos da profissão como fator que contribui para o estereotipo deturpado da enfermeira na sociedade, com impactos também na desvalorização da profissão. ${ }^{(17,18)}$

A representação estereotipada da enfermeira estende-se a seu corpo, forma e cor, por trazê-la como uma mulher, branca e bonita. Essa construção originou-se de um padrão de gênero-racial que reforça a formação da identidade profissional da enfermeira de forma excludente e discriminatória, uma vez que mulheres negras eram consideradas incompatíveis com o perfil profissional almejado e, portanto, deveriam ocupar postos de menor prestígio social, geralmente cargos de nível técnico. ${ }^{(19-21)}$

A imagem da enfermeira veiculada na mídia impressa e a influência desta divulgação na constru- ção da imagem social desta profissional podem ser analisadas, ainda, de diferentes formas ao longo das décadas, uma vez que marcos históricos contribuem para essas ocasionalidades. ${ }^{(2,5)}$

Este fato fica evidente quando analisamos o quantitativo de notícias que trouxeram a enfermeira como figura central. Na década de 1990 , a que registrou o maior quantitativo $(70 \%)$ de notícias mencionando a enfermeira como figura central, alguns marcos históricos importantes para a profissão merecem ser destacados, um deles a criação do Sistema Único de Saúde, regulamentado em 1990 pela Lei no 8.080 .

O processo de implementação do SUS provocou uma mudança nos modelos assistenciais de modo a atender seus princípios estruturantes - universalidade, integralidade e equidade, o que, por sua vez, demandou uma mudança no perfil dos trabalhadores em saúde. Como integrantes da equipe multidisciplinar em saúde, as enfermeiras precisaram redirecionar suas práticas profissionais e foi necessário reformular os currículos vigentes, convocando à discussão entidades de classe, escolas e organizaçóes de saúde, em busca de uma célere mudança na formação das enfermeiras.

Nesse sentido, a década de 1990 foi um marco para a categoria profissional no que diz respeito a ganhos legais para o exercício profissional. $\mathrm{Na}$ época, algumas conquistas incluíram a criação de entidades representativas da profissão e maior engajamento político para trilhar novos caminhos capazes de promover valorização e reconhecimento profissional. ${ }^{(7,9)}$

Entretanto, desde meados da década de 1980, já se observava esse movimento político da enfermagem brasileira mediante a aprovação da Lei $\mathrm{n}^{\mathrm{o}}$ 7.498/86. Esta Lei regulamentou o exercício profissional de enfermagem e estabeleceu como atividades não privativas a estas profissionais na coordenação de enfermagem, participação no ensino nas escolas de enfermagem, direção de escolas de enfermagem e participação nas bancas examinadoras de práticos de enfermagem, além do próprio exercício da enfermagem. ${ }^{(22,23)}$

Deste modo, os resultados do estudo evidenciam como diferentes momentos políticos do Brasil 
desvelou enfoques distintos da imagem da enfermeira nas mídias impressas assim como uma publicação cada vez mais frequente ao longo do recorte temporal dos 30 anos reiterando a influencia das mídias impressas enquanto meio de comunicação que reforça o contexto politico, social e histórico contribuindo para solidez da imagem da enfermeira de acordo com o exposto no momento presente.

Como limitação do estudo assinalamos a utilização apenas de texto escrito, uma vez que o material iconográfico das notícias não foi objeto de análise. Como as imagens publicadas pelo jornal intencionam ilustrar e/ ou reforçar a ideia transmitida pela notícia, incorporar esta análise poderia ter proporcionado achados complementares. Assim como, a utilização de um único jornal como fonte documental, com descritores específicos para retratar o objeto de estudo.

\section{Conclusão}

O estudo apresentou um Panorama da Imagem Social da Enfermeira divulgada na Mídia Impressa no período de 1970 a 1999. Podemos inferir, com base nos dados analisados, que apesar do significativo quantitativo de notícias publicadas a respeito do tema durante o período analisado, isso pouco contribuiu para a construção da imagem da enfermeira enquanto profissional de saúde na sociedade brasileira porque a maior parte das notícias apenas mencionou a enfermeira no texto ou utilizou o termo para caracterizar um objeto ou situação. A década de 1990 apresentou o maior número de notícias em que a enfermeira foi mencionada como figura central. Tal resultado pode estar relacionado com o momento histórico, que contemplou a implementação do SUS, a regulamentação da profissão e o fortalecimento dos movimentos de luta da categoria. Considera-se que o presente estudo amplia o conhecimento sobre a veiculação da imagem da enfermeira na mídia impressa ao correlacionar informaçôes divulgadas com momentos históricos de lutas e avanços na profissáo. Sugerimos a realização de outros estudos a respeito dos impactos e formas de uso das mídias impressas, uma vez que esses meios de comunicação atuam fortemente na construção e desconstrução da identidade profissional da enfermeira.

\section{Colaborações}

Brandão MF, Silva GTR, Teixeira GAS, Nascimento LF, Queirós PJP, Peres MAA, Laitano ADC e Santos VFPA contribuíram com a concepção do projeto, análise e interpretação dos dados, redação do artigo e aprovação final da versão a ser publicada.

\section{Referências}

1. Santos VL, Ferraz AF, Diogo AJ, Souza RM. A imagem de enfermeira e do enfermeiro percebida por alunos ingressantes no curso de graduação. Rev Bras Enferm. 1988;41(3/4):241-51.

2. Cavaca AG, Vasconcellos-Silva PR, Ferreira P, Nunes JA. Entre evidências e negligências: cobertura e invisibilidade de temas de saúde na mídia impressa portuguesa. Cien Saude Colet. 2015;20(11):3569-80.

3. Kneodler TD, Paes GO, Porto FR, Nassar PR, Oliveira AB. Nursing throughout war times: political propaganda and professional valorization (1942-1945). Rev Bras Enferm. 2017;70(2):407-14.

4. Martinez M, Pessoni A, Silva M, Ribeiro V. Assessoria de imprensa, narrativas midiáticas e saúde: simbiose de fontes, jornalistas, leitores, personagens e afetos. Intexto. 2017;0(38):197-224.

5. Silva AR, Padilha MI, Backes VM, Carvalho JB. Identidade profissional de enfermagem: uma perspectiva através das lentes da mídia impressa brasileira. Esc Anna Nery. 2018;22(4):e20180182.

6. Volpe CR, Aguiar LB, Pinho DL, Stival MM, Funghetto SS, Lima LR. Erros de medicação divulgados na mídia: estratégias de gestão do risco. RAHIS. 2016;13(2):97-110.

7. Sousa RC. Associativismo feminino e participação política: um estudo sobre as bases sociais de apoio à Ditadura Militar em Curitiba (19641985). Estud Hist. 2018;31(65):389-412.

8. Sreeja v N, Nageshwar V. Public Perception of nursing as a profession. Int J Res Appl Sci Biotechnol. 2018;5(5):15-9.

9. Laitano AD, Silva GT, Almeida DB, Santos VP, Brandão MF, Carvalho AG, et al. Precarização do trabalho da enfermeira: militância profissional sob a ótica da imprensa. Acta Paul Enferm. 2019;32(3):305-11.

10. Figueiredo AM, Souza SR. Como elaborar projetos, monografias, dissertações e teses: da redação científica à apresentação do texto final. 3rd ed. Rio de Janeiro: Lumen Juris; 2010.

11. Sá-Silva JR. Almeida CD, Guindani JF. Pesquisa documental: pistas teóricas e metodológicas. Rev Bras História Ciênc Sociais. 2009; 1(1): 1-15.

12. Marres N, Weltevrede E. Scrapin the social? J Cult Econ. 2013;6(3):313-35.

13. Amaral M. Oh, meu Deus! Manchetes e singularidades na matriz jornalística melodramática. Rev ECO-Pós. 2009;10(2):

14. Melo JM, Assis F. Gêneros e formatos jornalísticos: um modelo classificatório. Intercom Rev Bras Ciênc Comun. 2016; 39(1):39-56. 
15. Lopes P. "Géneros literários e géneros jornalísticos: uma revisão teórica de conceitos." Biblioteca Online de Ciências da Comunicação; 2010. [citado 2020 Nov 25]. Disponivel em: https://core.ac.uk/download/ pdf/54050682.pdf

16. Haron Y, Reicher S, Riba S. Factors influencing nursing career choices and choice of study program. Health Mark Q. 2014;31(2):167-77.

17. Colpo JC, Camargo VC, Mattos SA. A imagem corporal da enfermeira como objeto sexual na mídia: um assédio a profissão. Cogitare Enferm. 2006;11(1):67-72.

18. Andrade JB, Cavalcante MB, Apostolico MR. Marketing pessoal e enfermagem: projeção para visibilidade social do enfermeiro. Enferm Foco. 2017;8(1):82-6.

19. Oliveira EB, Carvalho RA, Teixeira E, Zeitoune RC, Sabóia VM, Gallasch $\mathrm{CH}$. Factors Involved In The Training Of Resident Nurses: View Of Alumni From A Residency Program. REME Rev Min Enferm. 2017; 21:e-1064.
20. Lombardi MR, Campos VP. A Enfermagem no Brasil e os contornos de gênero, raça/cor e classe social na formação do campo profissional. Rev ABET. 2018;17(1):28-46.

21. Pizzinato A, Hamann C, Tedesco PC, Jalmusny YM. Aspectos étnico-raciais e de gênero na inserção universitária de jovens africanas no Brasil. Rev Bras Educ. 2017;22(70):732-51.

22. Brasil. Lei $n^{\circ} 2.604$, de 17 de setembro de 1955. Regula o Exercício da Enfermagem Profissional. Diário Oficial República Federativa do Brasil; 1955 [citado 2020 Jul 25]. Disponível em: https://www2. camara.leg.br/legin/fed/lei/1950-1959/lei-2604-17-setembro-1955361190-publicacaooriginal-1-pl.html

23. Silva AR, Padilha MI, Bellaguarda ML, Teodosio SS. 0 processo de (re/de) construção da identidade profissional de enfermagem na mídia jornalística brasileira: 1980-1986. Texto Contexto Enferm. 2019;28:e20170590. 